\title{
Dever de informação em tempos de pandemia sob a perspectiva da boa-fé objetiva: lições para uma cidade inteligente
}

\author{
Duty of information in times of pandemic under the perspective of \\ objective good faith: lessons for a smart city
}

\author{
Daniel Bucar ${ }^{\mathrm{a}}$ (1) \\ Claudio Franzolin ${ }^{\mathrm{b}, ~ *}$ (iD)
}

Caio Ribeiro Pires ${ }^{c}$ (D)

\begin{abstract}
RESUMO: O presente trabalho, conforme o método sistêmico e embasado pela pesquisa bibliográfica, visa trazer um panorama sobre como o direito trata a questão da informação. Portanto, de início, fixa-se sua qualificação como bem jurídico autônomo e merecedor de proteção específica. Após, destaca-se a importância da boa-fé objetiva nas relações jurídicas que tem como objeto a informação cuja uma das partes busca acessar e a outra detém o controle. Nesse sentido, o princípio torna obrigatórios os padrões de condutas destinados a garantir a qualidade e facilidade do entendimento da informação que se deve reportar. Enfim, estudam-se os influxos desse cenário na relação entre município e seus habitantes, principalmente ao que toca a construção das cidades inteligentes- apontando-se certas lições trazidas pela pandemia para se pensar os problemas jurídicos advindos de tais situações.
\end{abstract}

Palavras-chave: Dever de Informação; Boa-fé Objetiva; Cidades; Direitos Fundamentais.

ABSTRACT: The present study aims to analyse bring a perspective how the law deals about duty of information. Therefore, at the outset, its qualification is succinctly defined as an independent legal asset and deserves protection by itself. Then, the constitutional provisions and other norms which regulate the duty of information are analyzed; it even analyzes the importance of information and its relevance to awaken confidence in the behavior of citizens, especially in the context of local information in the relationship between the Municipality and its inhabitants. The systemic method is adopted and based on the literature review. Characteristics of the information are pointed out and the importance of it being qualitative and intelligible in Brazilian law. As for the pandemic situation, the importance of the duty to inform, but which must be interpreted, taking into account the principle of objective good Faith.

Keywords: Duty of Information; Good Faith; Cities; Fundamental Rights.

\footnotetext{
${ }^{a}$ Faculdade de Direito, Universidade do Estado do Rio de Janeiro, Rio de Janeiro, RJ, Brasil.

b Programa de Pós-Graduação em Direito, Universidade do Estado do Rio de Janeiro, Rio de Janeiro, RJ, Brasil.

'Centro de Ciência Humana e Sociais Aplicadas, Pontifícia Universidade Católica de Campinas, Campinas, SP, Brasil.

* Correspondência para: Caio Ribeiro Pires. Endereço: Rua Professor Doutor Euryclides de Jesus Zerbini, Parque Rural Fazenda Santa Cândida, Campinas/SP, CEP: 13087571. E-mail: cfranzol30o@gmail.com.

Recebido em/Received: 15/08/2020; Aprovado em/Approved: 30/11/2020.
}

Artigo publicado em acesso aberto sob licença $\mathrm{CC} B Y 4.0$ Internacional $($ C) 


\section{INTRODUÇÃO}

A crise sanitário-econômica provocada pelo SARS-COV-2 é, também, uma crise informacional. Ilustre-se com apenas um exemplo, de muitos. Durante o período da pandemia, o Presidente da República, em franca guerra contra o necessário isolamento social, lançou a campanha "O Brasil não pode parar". Neste contexto, houve pronunciamento do Supremo Tribunal Federal, em sede liminar, para impedir a circulação desta publicidade, fundamentando-se na proteção à saúde da população'.

Nessa perspectiva, discutir o vínculo entre informação e direito parece cada vez mais relevante, razão pela qual o trabalho aborda o assunto. Mais especificamente, o texto analisa a tutela do direito de o Administrado ser informado pela Administração Pública, com enfoque principal na transmissão de informações entre o Município e seus habitantes.

Segundo um recorte de maior delimitação, (i) o texto busca identificar e qualificar o direito de ser informado à luz do ordenamento jurídico brasileiro. Depois, (ii) na perspectiva das classificações operadas, afirma-se a incidência da boa-fé objetiva na transmissão de informações. Enfim, a partir do raciocínio dogmático construído, (iii) analisa-se a relação informacional que deve se estabelecer entre o município e seus administrados durante a implementação de cidades inteligentes.

\section{DA INFORMAÇÃO EXIGÍVEL AO PADRÃO DE INFORMAÇÃO SINDICÁVEL: A RELAÇÃO ENTRE ADMINISTRAÇÃO PÚBLICA E ADMINISTRADO SOB O VIÉS DA BOA-FÉ OBJETIVA.}

\section{A tutela dos novos bens jurídicos e a informação.}

Diante de uma publicação engajada em reunir as mais diversas contribuições, das mais diferentes áreas, a respeito do tema da informação um importante exercício será o de qualificá-la de acordo com a Teoria Geral do Direito. Aliás, ressalte-se que aqui se menciona, de forma pensada, esta disciplina de forma expansiva, não a taxando de Teoria Geral do Direito Civil. Ora, frente a um ordenamento que tem como norma principal e superior a Constituição da República todas as disciplinas jurídicas devem respeitá-la. Portanto, a distinção entre direito público e privado torna-se muito mais quantitativa do que qualitativa (MORAES, 2010).

Conforme esta perspectiva, encontra-se a qualificação que talvez melhor reflita o lugar de destaque ocupado hoje pela informação no direito brasileiro, a de objeto da relação jurídica. Tal posição classificativa implica no reconhecimento de que ela é um bem jurídico por si só. Por sua vez, entendê-la à luz deste conceito significa considerar a informação uma necessidade humana cujo ordenamento jurídico impõe que seja tutelada por meio de seus instrumentos (TEPEDINO, 2006; PERLINGIERI, Pietro, 2002). Enfim, a partir deste substrato verifica-se, sem dúvidas, correta a afirmação da existência, no Brasil, de um direito de ser informado.

Ressalte-se que esta constatação reflete duas das principais características da constitucionalização do direito civil: I) a tutela não só das relações patrimoniais, mas também extrapatrimoniais, além da II) historicidade e relatividade da tutela dos bens

\footnotetext{
1 STF. MC ADPF 669 DF.: Rel. Min. Roberto Barroso. Dt Julgto 31/3/2020, DJe:03/04/2020, disponível em: http://www.stf.jus.br/arquivo/cms/noticiaNoticiaStf/anexo/ADPF669cautelar.pdf, acesso em: 22/10/2020.
} 
jurídicos. Quanto ao primeiro elemento, a tutela de um direito à informação é uma das grandes provas de que os interesses da pessoa humana não precisam estar dotados de valor econômico, ou dos pressupostos necessários para compor um direito subjetivo de propriedade, para se tornarem bens jurídicos. Assim, a suscetibilidade à comercialização e a possibilidade de se amoldar a uma titularidade ou domínio, tão importante à tutela jurídica de direitos no Estado Liberal, não são mais essenciais no Estado Social.

Desta forma, constituem interesses tão dignos de tutela quanto os patrimoniais - aliás, até mais - aqueles que impliquem na proteção dos direitos existenciais da pessoa humana e do exercício dos direitos de cidadão dentro do Estado Democrático de Direito. Nesse sentido, ganharam as páginas dos livros, como exemplo dessa transformação, a informação como bem jurídico e o direito de ser informado, ou seja, de receber notícias, ideias verdadeiras, sobre a situação político-social do país (PERLINGIERI, 2002; TEPEDINO; OLIVA, 2020).

Já o segundo aspecto demonstra que o direito não se modifica de acordo com as forças da natureza, tampouco evolui sempre em curva ascendente. Cada ordenamento jurídico é fruto de um tempo e de uma gama de escolhas políticas. Não por outro motivo a importância do direito à informação aumenta na sociedade tecnológica. Todavia, sua proeminência no direito brasileiro também coincide com o tratamento que a Constituição e a lei ordinária lhe outorgam.

Mais especificamente ao que importa a este trabalho, a informação como interesse do administrado, a ser tutelado no seio de suas relações jurídicas com a Administração Pública, se mostra sob múltiplos prismas conforme o viés normativo acima enunciado. Sublinhe-se que o direito de acesso à informação, de modo geral, está amparado em vários direitos fundamentais, tais quais, Art $5^{\circ}$, IV, X, XII, XIV, XXXIIII, XXXIV-b, LX, LXXII, CR. Ainda, no âmbito da administração pública, há o art. 37, § $3^{\circ}$, II além do art. 216, § $2^{\circ}$ do mesmo diploma.

Tais normas de caráter aberto foram se adensando ao ponto de chegar à criação de um estatuto jurídico que garante o direito de ser informado em face do Estado, a Lei de Acesso à Informação. Conforme uma visão geral, a Lei 12.527/11 (LAl) buscou disciplinar (a) o acesso permanente à informação governamental, especificamente a todos os atos da administração pública, fortalecendo, assim, o controle social e (b) o direito de o administrado controlar seus dados pessoais, coletados por qualquer ente público, bem como conhecer a estrutura de tratamento de tais informações (BARCELLOS, 2015. p. 1742).

Quanto ao primeiro escopo, a normativa estabeleceu duas orientações para divulgação de seus atos: (i) disponibilização ativa das informações por meio de divulgação em sítios eletrônicos (Art. $8^{\circ}, \mathrm{LAl}$ ) e (ii) atendimento, mediante provocação do interessado, a solicitações de fornecimento de informação (Art. 10 e seguintes).

Ressalte-se que a lei não se preocupou apenas com a previsão de um procedimento hábil a garantir o acesso à informação, mas, também, estabeleceu parâmetros que definem como se transmitir a informação. Nesta direção, dispõe sobre os dados mínimos que devem constar na resposta aos pedidos de informação (art. $8^{\circ}$, §1 ${ }^{\circ}$, LAI) e requisitos mínimos que todo sítio eletrônico da Administração Pública deve conter (art. $\left.8^{\circ}, \S 3^{\circ}, \mathrm{LAI}\right)$. Sob outro viés, institui a obrigatoriedade de que a Administração Pública ofereça um serviço institucional responsável por divulgar informação ao administrado, além de orientá-lo (art. $9^{\circ}$, caput, incisos I e II da LAI).

Nada obstante o regramento aparentemente exaustivo, a lei não deixa de prever uma espécie de cláusula geral ( $\left.\operatorname{art.} 8^{\circ}, \S 2^{\circ}, \mathrm{LAl}\right)$, que fixa o dever dos órgãos, entidades 
públicas, utilizarem-se de todos os meios e instrumentos que dispuserem para informar os administrados. A partir do dispositivo, conclui-se que a lei não enumera taxativamente os requisitos necessários para assegurar a suficiência do conteúdo da informação ou dos serviços essenciais para garantir o acesso a ela. Portanto, subsiste não só um direito meramente quantitativo, e sim qualitativo. Diante do caso concreto será preciso que a Administração Pública empenhe seus melhores esforços com o fim de transmitir a informação e assegurar o seu entendimento pelo administrado que a recebe.

Tal perspectiva do direito à informação é pouco mencionada tanto pela doutrina quanto pela jurisprudência. Segundo busca realizada no Supremo Tribunal Federal, Superior Tribunal de Justiça e Tribunal de Justiça dos Estados do Rio de Janeiro e São Paulo, a maioria dos julgados encontrados sobre a Lei de Acesso à Informação continha decisões em ação civil pública. Via de regra, pretendia-se obrigar a Administração Pública à divulgação de dados sobre gastos do erário, contratações, dentre outras informações².

No entanto, a questão da qualidade da informação - merecedora de tutela e sindicável frente ao Poder Público - não deixa de merecer um olhar atento, especialmente neste tempo de crise pandêmica. E nos ditames da boa-fé objetiva encontram-se contornos dogmáticos aptos à estabelecer os relevantes standards de conduta exigíveis da Administração Pública durante a transmissão da informação, os quais tornam a concretização dos direitos do Administrado mais efetiva.

\section{O dever de informar advindo da boa-fé objetiva como fundamento da obrigatoriedade de comunicação adequada.}

A título de introito, cumpre asseverar, conforme Glauco Arbix, que a crise gerada pela Covid-19, até o momento deixou três grandes "marcas" (expressão do autor citado).

Entre os impactos apontados, iremos destacar a conexão da disseminação do medo e da perplexidade entre a coletividade ${ }^{3}$. Nessa direção, demonstraremos a interface de tais elementos com o dever de informação à luz do princípio da boa-fé objetiva. É que a informação, numa sociedade marcada pela rapidez da comunicação torna-se cada vez mais indispensável na tomada de decisão.

Ademais, ela também estabelece nítida conexão com o que se propaga sobre a COVID, considerando: i. diversidade das fontes informacionais; ii. a necessidade, além da importância, do acesso à informação pública; iii. diversidade de dados, recomendações e orientações na forma de combate à doença conforme diferentes esferas do governo, mas também da sociedade civil; iv. modificações no conteúdo das informações, conforme avançam pesquisas e análises sobre a pandemia, as quais são reelaboradas (FREITAS; NAPIMOGA; DONALISIO, 2020) e acrescidas às demais já veiculadas.: Dentro

\footnotetext{
${ }^{2}$ Nesta perspectiva recente julgado determinando a prestação de informações sobre a privatização de determinada empresa de energia elétrica, requeridas por grupo de sindicato, o qual se encontra nos autos do STJ. Agravo Interno no Mandado de Segurança $n^{\circ}$ 23529/DF. Rel. Min. Gurgel de Faria. $1^{a}$ Seção. Dt julgto: 12/12/2018. Dje: 19/02/2019, disponível

https://scon.stj.jus.br/SCON/GetInteiroTeorDoAcordao?num_registro=201701128760\&dt_publicacao=19/02/2019. Acesso em: 22/10/2020.

${ }^{3}$ Quais sejam, elevado número de mortes e sequelas, situações as quais afetaram as populações em curto espaço de tempo; ii. diminuição do emprego, de salários e de renda, desorganização da economia e consequente aumento das desigualdades e da pobreza; iii. corrosão institucional e disseminação do medo e da perplexidade na sociedade (ARBIX, Glauco, 2020).
} 
deste contexto, o administrado resta exposto a uma diversidade de entendimentos, mudanças de perspectiva, que lhe exige um esforço maior para compreender as informações recebidas e um cuidado redobrado da Administração Pública ao repassálas.

Apontam-se, assim, os seguintes questionamentos: como articular saúde e o ente municipal, considerando a complexidade da Administração pública, a qual se distribui entre as três esferas da Federação para efetivar o dever de informação? Como as informações devem ser produzidas, comunicadas e difundidas para a coletividade, consoante o exercício da atividade administrativa, cujos destinatários são diversos, ante a miríade de diferentes situações existenciais integradas em uma sociedade cada vez mais multicultural e plural?

Nessa rota, tais aspectos são importantes porque, à medida que as informações são elaboradas, armazenadas, difundidas e reelaboradas, elas exercem nítidos impactos, verdadeiros rearranjos sociais, além de gerarem nos indivíduos certas expectativas legítimas, que repercutem na maneira deles tomarem uma posição ou adotarem uma conduta. Um exemplo é a forma como as decisões político-administrativas dos governantes podem ser conduzidas conforme eles sejam mais sensíveis ou não aos saberes científicos.

Em suma, as incertezas sobre a COVID-19, por si só, já promovem um ambiente de desencontro de informações em que elas são reelaboradas constantemente, ante o fato de que os estudos sobre o dito vírus ainda estão sendo feitos.

Acrescente-se, ainda, no Brasil, as contradições que acentuam, ainda mais, o ambiente de perplexidade e dúvidas. Por exemplo, quanto à eficiência ou não de certo medicamento e se ele deve ou não ser prescrito pelo médico; quanto às informações desconexas sobre a gravidade ou não da pandemia; quanto à falta de articulação no seu enfrentamento, pois, uns agentes políticos defendem o isolamento a partir de informações baseadas em estudos científicos, outros as rejeitam e defendem a flexibilização, o que já culminou, inclusive, na judicialização ${ }^{4}$.

Nessa rota, qual a interconexão entre informações, Covid-19 e o que tem de relevante no princípio da boa-fé, sob a perspectiva do direito público, para promover a tutela mais efetiva dos cidadãos nesse contexto apresentado?

Para amparar a articulação entre o princípio da boa-fé e sua importância para o presente trabalho, esclareça-se, inicialmente, que tal norma desempenha algumas funções no âmbito do direito privado. Em direção semelhante, estes mesmos papéis permitem estabelecer uma maneira de preencher o conteúdo do dever de informação no âmbito do direito público e, até, determinar a incidência da referida norma em tal seara.

Para apontar, portanto, a relação entre o princípio da boa-fé objetiva e sua relevância para o conteúdo informacional sobre COVID-19, é necessário tomarmos como ponto de partida, três premissas: i. maior conexão de sentidos entre direito público e direito

\footnotetext{
${ }^{4}$ É a situação, por exemplo, da ação civil pública manejada pelo Ministério Público do Estado do Rio de Janeiro e Defensoria Pública, também do Rio de Janeiro, haja vista, conforme se extrai da inicial, que tal medida se deu ante o Chefe do Executivo Estadual (RJ) publicar, em edição extraordinária do Diário Oficial, o Decreto n 47,112, de 05/06/20, flexibilizando as regras de isolamento social no Rio de Janeiro a partir do dia 06.06, a permitir a reabertura de shoppings centers, restaurantes, centros comerciais, cultos religiosos, além da prática de exercícios ao ar livre e diversas outras atividades, enquanto a pandemia de COVID-19 seguia em curva ascendente no Estado. Justamente, o Parquet pede que o governo estadual apresente dados que indiquem que a retomada da atividade se baseia em estudos, levantamentos, dados em saúde, vigilância sanitária, mobilidade urbana, segurança pública e assistência social. Distribuída por dependência nos autos do processo nº068461-21.2020.8.19.0001 (MINISTÉRIO PÚBLICO DO RIO DE JANEIRO, 2020).
} 
privado, os quais não podem ser mais estudados de forma estanque (LORENZETTI, 2010, p. 39; MORAES, 2015. p. 90); ii. fortalecimento do Estado Constitucional, como superador do Estado de Direito, na substituição "do princípio da legalidade pelo princípio da constitucionalidade" (PEREIRA; SILVA, 2006), de maneira que os princípios ganham força obrigatória e passam a desempenhar função no processo hermenêutico; iii. a superação do conceito 'geral' e 'abstrato' na noção de povo e de cidadão, ante o multiculturalismo, pluralismo, pressões setoriais conforme situações existenciais diversas, além do reconhecimento de novos direitos à medida que se destacam as vulnerabilidades de categorias de sujeitos distintos.

Essas premissas amparam não só a constitucionalização do direito privado a partir da prevalência dos interesses extrapatrimoniais, mas também a consideração dos reflexos da aplicação da norma na esfera jurídica de terceiros ante a necessária visão social das relações entre particulares (BRANCO, 2002). De modo extensivo, também fazem o direito público dotar-se de maior conexão de sentido com os valores constitucionais, seja o direito administrativo, penal, ambiental, dentre outros.

O princípio da boa-fé, nessa perspectiva, conduz o intérprete para avaliar o contexto onde está inserida a relação privada, ou seja, o caso concreto; e, dada a vagueza semântica do dito princípio, promove o reenvio a um valor. Em suma, ele expressa, concomitantemente, um princípio, um standard comportamental e uma cláusula geral (MARTINS-COSTA, 2015). Detendo-se, por exemplo, na classificação de Judith MartinsCosta, a autora destaca as seguintes funções da boa-fé: i. função hermenêutica, de maneira que a boa-fé desempenhe a interpretação contratual (art. 113, do Código Civil - Civil); ii. função de colmatação de lacunas e criadora de deveres às partes (art. 422, do (Civ); iii. função corretora da boa-fé para direcionar condutas no tráfico negocial no momento do exercício de direitos, faculdades, pretensões, exceções, ações e ônus (MARTINS-COSTA, 2015). Ou seja, valoriza-se a confiança e a tutela das expectativas legítimas dos envolvidos numa dada relação jurídica, e coíbe o abuso de direito (art. 187, do CC.).

Apontadas essas funções, cabe expor sobre a possibilidade da incidência da boa-fé objetiva no âmbito do direito público.

Edílson Pereira Nobre, estudando a evolução desde a não aceitação do princípio da boa-fé na seara juspublicística, parte de Sainz Moreno que estabelecia três óbices para não aplicação de tal norma na esfera do direito público: i. a diferença qualitativa das partes na relação jurídico-administrativa; ii. a circunstância de que toda a relação administrativa estaria concentrada no princípio da legalidade e iii. a distinção da natureza em relação aos interesses em jogo envolvendo a Administração e o particular.

No entanto, se o próprio direito privado é coordenado juntamente com mandamentos publicistas, com mais razão justifica-se a aplicação do princípio da boa-fé também às relações das quais participa o Estado, afinal, detentor de poder e de supremacia, mais do que nunca deve exercer seus direitos em conformidade, também, conforme a boafé (NOBRE, 2002). De igual maneira, pode-se justificar a incidência do referido princípio no âmbito do direito público considerando que ele tem fundamento no princípio da solidariedade social (art. $3^{\circ}$, I, da Constituição Federal) (SCHREIBER, 2012, 107).

Sob a perspectiva mais precisa, nas relações entre particulares e o Estado, Judith Martins-Costa, destaca a boa-fé objetiva, considerando como "norma asseguradora da manutenção de situações consolidadas desde que geradoras de expectativas legítimas para os administrados" em suma, prossegue a autora, se a Administração Pública tem maior poder, tem também responsabilidade ampliada, e deve seguir a boa-fé objetiva. 
Porém, realça que da mesma forma a boa-fé também se aplica em detrimento do administrado quando adota condutas desleais (MARTINS-COSTA, 2016).

Demonstrada a incidência da boa-fé objetiva no âmbito da administração pública, podemos, a partir daí, estabelecer pontos de conexão entre as informações públicas e as especificidades delas no âmbito da situação existencial dos administrados.

Com efeito, segundo SARLET e MOLINARO, cuidam-se de ações de informar, informarse e de ser informado (SARLET, MOLINARO, 2016). Ainda, explicam, a informação "assume uma dimensão individual, na condição de direito subjetivo de acessar informação perante qualquer sujeito de direito". Prosseguem, dizendo que o direito de acesso à informação "imanta necessariamente proteção dos direitos de personalidade" (SARLET, MOLINARO, 2016. p. 16).

Em tempos de pandemia ganham destaque as informações sobre o desenvolvimento da doença que é sua força motriz. Ora, essas informações transmitidas pelo Poder Público, principal gestor da crise sanitário-econômica, devem corresponder â confiança que o administrado deposita na Administração Pública segundo os ditames do Estado Democrático de Direito. Além disso, a emissão de tais informações é apta a gerar legítima expectativa por parte dos administrados.

Outro aspecto relevante sobre a informação encontra-se na atividade necessária para sua transmissão, conforme Eduardo Rocha Dias. Afinal, ela deve servir ao fim de prevenir acerca de eventos futuros. Não só, serve também para "adotar medidas destinadas a minimizar ou a tornar aceitáveis os riscos socialmente criados decorrentes do progresso civilizatório e das limitações da ciência que não se deixam determinar espacial, temporal e socialmente" (DIAS, 2008. p. 39). Ademais, no contexto do Estado Constitucional brasileiro, vigente sobre um território marcado por contradições e desigualdades, se por um lado expande-se o alcance da veiculação informativa, os destinatários dela estão em situações existenciais distintas, assim, o conteúdo comunicacional da informação pode ser assimilado de uma outra forma, ou nem sequer ser assimilado.

Ainda, há outro aspecto relacionado à informação, o qual ganha destaque no presente estudo, qual seja, a situação de risco decorrente da pandemia e os impactos dela na vida dos indivíduos. Ou seja, a imprevisibilidade, a instabilidade, a diversidade de informações torna necessário que o Administrador atue a partir de uma tutela mais sensível para os cidadãos. Dito de outra forma, não basta apenas informar, deve se informar de modo qualificado e direcionado aos mais distintos públicos.

Nesse contexto, chama-se atenção para o dever de informar por parte da Administração e o direito de ser informado do administrado. O cotejo destas situações jurídicas deve ser articulado com a obediência a certos deveres de conduta, que, em verdade, preenchem o conteúdo do princípio da boa-fé objetiva. Captando os ensinamentos de Izabel Cristina da Silva Sampaio, ao analisar detalhadamente, o conteúdo do dever de informação em matéria ambiental, podemos apreender os ensinamentos da autora, no intuito de adaptá-los para o presente estudo. Nessa rota, a mesma destaca a importância da veracidade da informação, pois permitirá ao cidadão opinar, criticar ou agir diretamente, quando for confrontado por um determinado conjunto de fatos.

A autora, então, aponta outras quatro características acerca da informação ambiental. Inicia-se, apontando como primeiro aspecto essencial da informação, a acessibilidade. Ou seja, "é preciso que se consiga acessar a informação, de maneira que a sua obtenção, quer nos meios, quer na forma, seja simples e isenta de entraves para todo e qualquer cidadão" (SAMPAIO, 2013. p. 14242-14243). Nesse contexto, será 
insuficiente pensar padrões de conduta que facilitem a divulgação da informação de modo universal. Em sentido contrário, precisa-se atentar para quem será o seu receptor, a fim de definir o conteúdo da cooperação que se exige por força da boa-fé objetiva nas relações informacionais. Inclusive, será necessário pensar nas condições de certos grupos (analfabetos, idosos), que os deixam mais suscetíveis -vulneráveis- à violação do direito expatrimonial (KONDER, 2015, p. 5) de ser informado.

Outra característica que o supracitado texto destaca é a qualidade da informação. Assim, explica, sob a perspectiva da informação ambiental, que ela deve ser amparada em dados técnicos, parâmetros, padrões e índices, mas, ao mesmo tempo, ser compreensível ao cidadão comum. O cidadão pode ostentar grande conhecimento técnico sobre um assunto, mas não ter condições de avaliar dados técnicos. Então, "a forma como as informações são divulgadas pela Administração pública, deve ser explicativa, esclarecedora, com o intuito de outorgar ao cidadão o direito de livre formação das suas opiniões com base nos dados científicos".

A terceira característica é a clareza. De fato, conforme a autora, caracterizar a informação ambiental significa afirmar que ela deve ser detalhada e técnica. Mas tal situação não pode ser um empecilho para informar a população independentemente do grau de instrução que ela apresenta.

Aplicando essa característica sobre a informação em matéria de pandemia, sobre os dados de isolamento, uso de medicamento e qualidades terapêuticas, levantamentos estatísticos, diagnósticos e evidências da contaminação, em que pese sejam fundadas em dados técnicos, é preciso que a Administração Pública reste aparelhada de meios para transmitir as questões envolvendo a pandemia de forma que se faça entender pelo administrado Por exemplo, se acaso for preciso esclarecer uma comunidade onde prepondera baixo nível de escolaridade e analfabetos, a administração pública deve valer-se de outros meios comunicacionais, como por exemplo, vídeos institucionais, linguagens simples, simulações, mídias em redes sociais, etc.

Por derradeiro, a outra característica da informação em matéria ambiental apontada no trabalho supracitado é a celeridade (SAMPAIO, 2013. p. 14242-14243). Segundo a autora, em matéria ambiental as informações precisam circular de forma rápida. E isso demanda, mais uma vez, meios para que se evite o tanto quanto antes danos em detrimento de vidas humanas e também do próprio meio ambiente. Tal característica também se aplica quanto às informações a serem fornecidas sobre a pandemia, os riscos, a forma mais eficaz de combate e enfrentamento dela. Ademais, é importante que as informações sejam claras sobre a dimensão dos riscos da doença para a população. Não só, é importante que se avalie, que haja cautela na sua divulgação, o que evitará distorções e contradições em curto espaço de tempo.

Reitere-se que o estabelecimento de parâmetros de aferição do regular cumprimento do dever de informar será expediente imprescindível no presente tempo pandêmico. A partir dele alimenta-se a tutela da confiança na forma de efetivar o direito fundamental à saúde, o princípio da solidariedade e o regular o exercício das liberdades individuais em prol do interesse público. Desta forma, não se trata, apenas, de normas editadas, publicadas pelos poderes públicos para enfrentamento da pandemia, mas, informações, coerência, considerando fatos, valores, a necessidade de aperfeiçoar o valor confiança e a segurança jurídica, pilares do Estado Democrático e Constitucional. 


\section{PODER PÚBLICO MUNICIPAL, A CIDADE INTELIGENTE E A TRANSMISSÃO DE INFORMAÇÃO: LIÇÕES DO CENÁRIO DE COVID-19 PARA O FUTURO.}

\section{A proximidade entre o município e o cidadão: razão de um dever de informar qualificado?}

A pandemia, devido às suas proporções, afetou os atos mais cotidianos praticados pelos cidadãos. O risco de contágio tornou os hábitos corriqueiros em perigosos, como sair às ruas, trabalhar fora de sua residência e frequentar escolas. Logo, esta crise tem, além dos impactos globais, nacionais - de cunho político-econômico - consequências diretas no funcionamento e organização das localidades próximas, onde a população vive. Tal situação, obviamente, ressoa com mais intensidade nos centros urbanos, onde, afinal, concentra-se a maioria da população5.

Conforme o direito brasileiro, o reflexo destes impactos - quando ocorridos no meio urbano- será tratado conforme o prisma das normas dirigidas à cidade. A partir do art.182, a Constituição da República ordena que o Poder Público desenvolva plenamente as funções sociais deste espaço e garanta o bem-estar de seus habitantes. Em idêntica perspectiva, o chamado Estatuto da Cidade (Lei 10.257/2001) reforça estas diretrizes e determina os meios específicos para realizá-las.

Nos ditames da Lei Maior, é o município (art. 182, caput, CR) o ente federativo responsável por concretizar os referidos ditames, os quais formam a política de desenvolvimento urbano (LIRA, 2015, p. 669). De fato, adequada à opção do constituinte, pois a municipalidade consiste em uma espécie de comunidade de vizinhos institucionalizada, onde as políticas públicas direcionam-se a melhorar o cotidiano das pessoas habitantes daquele território, como já afirmado por alguns autores (DANTAS; CASTRO, 2018. p. 107-109).

Embora não pareça correto afirmar a existência de um dever qualificado de informação no sentido de maior e mais importante do que aquele imputável à União e aos Estados, não deixa de ser verdadeira a percepção de que a transmissão da informação entre a municipalidade e seus habitantes será repleta de peculiaridades. Isso porque, devido à proximidade entre município e administrado, será por meio desta comunicação, ou, ao menos, segundo os dados divulgados por esse ente, que cada um poderá planejar o dia a dia, além de tomar difíceis decisões ao longo do período de isolamento social. Em que fase a cidade está em relação à contaminação? Diminuíram-se os riscos de trabalhar presencialmente? Devo resistir a uma retomada presencial? Quando voltar a levar crianças para escolas com segurança?

A resposta adequada e eficiente destas perguntas dependerá da ampla, em outros termos, qualitativa, divulgação de dados sobre os números de contágio e mortes na localidade. Esta questão não é nova, porém, o contexto de crise escancara a necessidade de uma distribuição da informação pelo município conforme os preceitos de uma gestão democrática, que devem perpassar a atividade de toda a Administração Pública no âmbito das cidades (LIRA, 2015. p. 675).

\footnotetext{
5 Em 1950, trinta percentuais (30\%) da população fixavam-se em áreas urbanas; em 2050, projeta-se uma estimativa correspondente a sessenta e oito percentuais (68\%) de pessoas vivendo em áreas urbanas (ONU - Organização das Nações Unidas. Nova Agenda Urbana foi adotada na Conferência das Nações Unidas sobre Habitação e

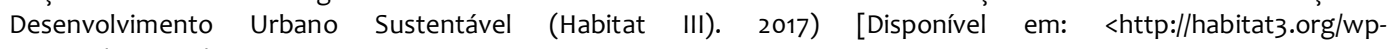
content/uploads/NUA-Portuguese-

Brazil.pdf?fbclid=IwAR2kolM7MtgBh6i57G4fxWeWpbK52Jr7sXIrGdBbJF81bF2GSzY527FWdAY > Acesso 1 julho 2020].
} 
Os desafios da concretização de tais objetivos são grandes. O cenário revelado nas cidades é de uma profunda desigualdade, inclusive no acesso qualitativo à informação. Tome-se, como exemplo, o debate sobre a volta às aulas de forma virtual nas universidades públicas. O cerne da questão encontra-se na falta de acesso à internet ou no acesso precário em determinadas regiões, que impediria uma grande parte dos alunos de completarem o semestre no modelo não presencial ${ }^{6}$. Em palavras diversas, o debate é justamente sobre acesso qualitativo à informação.

Nestes termos e principalmente quando a informação é necessária ao resguardo dos direitos fundamentais, como nos tempos de pandemia, a política do município jamais pode desconsiderar estas diferenças socioeconômicas. Os caminhos para atender esses anseios são diversos e impossíveis de se explorar nos limites deste trabalho.

Entretanto, cite-se apenas a necessidade de comunicação com as associações de moradores. Tais instituições constituem uma espécie de poder regulatório, organizacional, independente do direito formal, que determinam standards comportamentais específicos cujos moradores de comunidades adotam para boa convivência. Ou, dito de outra forma, pode se afirmar que estes órgãos realizam verdadeira gestão administrativa em lugares carentes, até mesmo, da presença do Estado (LIRA, 2015. p. 669; 683-684). Com efeito, esta comunicação pode ser essencial para que pessoas habitantes desses locais tenham informação suficiente para planejar o seu cotidiano, resguardar-se de perigos, tomar decisões livres, conscientes, enfim, preservar sua dignidade e condição de cidadão de um Estado Democrático.

Se o cenário da pandemia torna a necessidade de ser informado mais urgente e visível (repita-se, as pessoas precisam saber quantas vítimas falecem por dia de COVID-19, quantas se contagiam, que equipamentos utilizar para sair de casa com maior segurança) não se olvida que ela será imprescindível, em maior ou menor medida, todos os dias no meio urbano. Inclusive, este é um debate essencial de se incorporar entre as problemáticas da atual fusão da cidade com a tecnologia, verificada nos projetos de implementação das cidades inteligentes.

\section{O dever informacional do município no contexto das cidades inteligentes (smart cities)}

Há vários percalços relacionados aos espaços urbanos: urbanização desenfreada, excesso de geração de resíduos - típico de uma sociedade líquida (BAUMAN, 2007) - e, ainda, a falta de saneamento e infraestrutura. Os problemas são, portanto, variados. Diante de tal cenário, surgem problemas ambientais relacionados ao ar poluído, falta de acesso à água potável, falta de infraestrutura em matéria sanitária; todos relacionados à assimetria entre os habitantes da cidade, contexto que sempre afetará de modo direto os mais vulneráveis.

Por isso, Carla Canepa aponta que o foco da cidade é que ela passe a ser um modelo de "sustentabilidade baseado no bem-estar humano" (CANEPA, Carla, 2007. p 53) para todos. Sublinhe-se, assim, que nas cidades, por meio de uma atitude mais cooperativa

\footnotetext{
${ }^{6}$ Apenas com o fim de ilustrar o problema, segundo análise dos dados do questionário socioeconômico aplicado pelo Instituto Nacional de Estudos e Pesquisas Educacionais Anísio Teixeira (Inep), vinculado ao Ministério da Educação, um terço dos candidatos que buscaram vagas em universidades públicas pelo ENEM não tem acesso à internet , ("um terço dos candidatos às universidades não tem acesso à EAD”, Agência Brasil, 01 de abril de 2020, [acesso em: 13/08/2020], disponível em: https://agenciabrasil.ebc.com.br/educacao/noticia/2020-04/um-terco-dos-candidatos-universidadesnao-tem-acesso-ead.
} 
e compartilhada entre atores privados e públicos, espera-se que se assimilem valores sociais, coletivos, ecológicos, de maneira a articularem processos econômicos, tecnologia, qualidade de vida, enfim, bem-estar humano, para a atual e para as futuras gerações. É nesse sentido que se destacam as cidades inteligentes (smart cities) ${ }^{7}$. Ou seja, cidades inteligentes não se limitam a tecnologias inteligentes, internet das coisas ou, apenas, aparelhamentos de vigilância para solução de problemas urbanos.

Cidades inteligentes envolvem grande complexidade e grandes desafios: uma nova economia mais compartilhada, acessibilidade, dentre outros aspectos, e ainda, políticas sociais relacionadas à educação, saúde, previdência, saneamento entre outros aspectos (SANTOS, 2020). Enfim, trata-se de "viabilizar a sustentabilidade em todas as suas interfaces" (NALINI; SILVA NETO, 2017: p. 9). Afinal, não podemos nos manter restritos ao conceito de cidades inteligentes apenas sob a perspectiva de que ela se baseia em suportes tecnológicos e circulação de dados numa camada virtual, por meio das tecnologias inteligentes da informação. Tais aspectos, portanto, também devem ser considerados no contexto da pandemia.

Detendo-se no enfrentamento da pandemia de COVID-19, a Organização Mundial da Saúde defende o isolamento social. Nessa direção, repercutem em limitações e restrições de vários direitos fundamentais, como quarentena, cordão sanitário, tratamento e diagnóstico compulsórios, controle de venda e comércio de produtos, etc (AITH, 2020). Sob a perspectiva virtual, o uso da Inteligência Artificial (YANG, 2020), algoritmos (IA), Internet das coisas (IOT), Big Data, drones (D'AMORE, 2020), e demais tecnologias, para combate à pandemia, esbarra igualmente na proteção dos direitos individuais da pessoa humana em face do interesse coletivo. Porém, mesmo que munidas de propósitos aparentemente legítimos, estratégias que se valem de uma espécie de "exceção do interesse público" não poderão ultrapassar limites para atentar, de alguma forma, contra a axiologia constitucional.

Ou seja, as questões de informações obtidas a partir de tecnologias inteligentes não estão dissociadas, no contexto urbano, dos valores constitucionais. Como bem destaca, Harari, hoje, só a partir dos dedos, já se poderá obter a temperatura e a pressão sanguínea do indivíduo (HARARI, 2020). Não só! É possível até detectar o que faz o indivíduo sorrir, chorar. Enfim, novos tempos com os quais, a preocupação não é só em tempos de pandemia, mas, quais os desafios após a pandemia.

Neste contexto de cidades mais e mais aparelhadas, equipadas com novas tecnologias não significa que se possa utilizar este aparato com a simples justificativa de melhor solução dos problemas urbanos. Por isso, trouxemos, ainda que de forma breve, algumas considerações sobre cidades inteligentes. Elas não se limitam a utilização de tecnologia da informação. Cidades inteligentes significam cidades inclusivas, significam enfim, cidades que, embora aparelhadas com tecnologias, tenham em sua projeção o intuito de construir o bem-estar humano e os ambientes sustentáveis.

Neste contexto, cidades inteligentes também se curvam aos deveres informacionais, assegurando-se assim o livre desenvolvimento de sua personalidade no ambiente

\footnotetext{
7 Nesse sentido, vale ponderar, conforme Nalini e Levy, que a força semântica da expressão <cidades inteligentes> sugere menos do que realmente se pretende. Isto é, conforme os autores, há uma tendência de associar a expressão "cidades inteligentes", apenas, às possibilidades de controle oferecidas pelas tecnologias e equipamentos inteligentes(NALINI, José Renato; SILVA NETO, Wilson Levy, 2017: p. 3-18). . Em verdade, "a noção geral acadêmica e multidisciplinar de smart city congrega temas como: governança, vida em sociedade, mobilidade urbana, uso intensivo de dados e tecnologia, preocupação ecológica, usos e produção sustentável, utilização com finalidade pública das redes sociais, evidentemente com implicações nos estudos da economia e suas variações mais atuais: economia criativa, economia circular, economia colaborativa (sharing economy). (GUIMARÃES,; XAVIER, , 2016, p. 1384)
} 
urbano, o que inclui, por exemplo, mobilidade, liberdade, participação das decisões da vida da sociedade, dentre outros. Dito de outra maneira, espera-se que os projetos de smart cities passem a obedecer a todos os preceitos ora estudados de informação ao cidadão, garantindo, sempre que possível, sua autodeterminação informativa, participação, emitindo opiniões sobre os limites e potencialidades das tecnologias que modifiquem o dia a dia da localidade em que habita.

\section{CONCLUSÃO}

No contexto mundial, a Organização Mundial de Saúde - OMS declarou situação de pandemia, em 11/03/2020 e, por sua vez, surgiram questões inúmeras de natureza jurídica no mundo e obviamente, no Brasil.

Mencione-se, por exemplo, medidas de isolamento, quarentena, restrição de ingresso e saída do país, bem como restrições de locomoção interestadual, intermunicipal, além da requisição de bens e serviços. Porém, para que tais medidas funcionem, é preciso que os entes da Federação estejam aptos para difundirem as informações e que estas revelem a real situação da pandemia.

Não só, as informações divulgadas despontam expectativas na esfera dos administrados e, ainda, influenciam as decisões, as escolhas, as opiniões desses últimos. Desta forma, diante de uma perspectiva civil constitucional, superando a dicotomia entre público e privado, destaque-se que a informação é um bem jurídico, por si só.

Assim, é necessário que a Administração Pública empenhe seus melhores esforços com o fim de transmitir a informação e assegurar o seu entendimento pelo administrado que a recebe. O foco da análise voltou-se para perspectiva municipal porque é no ambiente do espaço urbano onde se nota, de forma mais sensível, a vida cotidiana dos indivíduos.

A partir daí, captando o princípio da boa-fé objetiva, sendo ele um princípio não exclusivo do direito privado, em interface com o direito público permite que se estabeleça uma análise do dever de informação sob o viés dos seus ditames. Permitese, por meio da referida norma, alcançar maior sensibilidade ao caso concreto na determinação de como atender o direito de ser informado conforme a órbita do direito administrativo. Segundo a ênfase aqui desenvolvida, tal itinerário tem grande utilidade no âmbito municipal, considerando a importância do espaço urbano e a proximidade com o cidadão.

Então, para melhor preencher o conteúdo do princípio da boa-fé no âmbito informacional, aponta-se alguns elementos que possam orientar o intérprete. Para tanto, ditos parâmetros foram captados a partir dos estudos realizados sobre informação ambiental, considerando a importância da informação entre a municipalidade e seus habitantes.

Acrescente-se, ademais, que informações aqui abordadas associam-se às medidas de contenção de expansão da pandemia, restrições de direitos fundamentais e monitoramento. Porém, e para além deste momento, ressaltamos que a preocupação contemporânea no âmbito das cidades, é que o os estudos foquem na realização concreta do bem-estar humano no espaço urbano. Nessa rota, apresentamos como exemplo, as cidades inteligentes (smart cities), haja vista que elas passam a ser consideradas não, apenas, focadas na eficiência tecnológica, mas, sobretudo, na realização do bem-estar humano para todos os cidadãos de forma sustentável. 
Em suma, informação, espaço urbano, tecnologia, direitos fundamentais, interconectam-se, e o princípio da boa-fé torna-se um importante canal axiológico para avaliar a qualidade da informação relacionada à pandemia. Assim, tutelam-se os direitos e interesses dos administrados, não apenas numa perspectiva formal, mas, também de maneira a fazer com que a informação seja entendida, pois só assim o dever de informar restará completamente obedecido.

\section{REFERÊNCIAS}

AITH, Fernando. Emergências em saúde pública em estados democráticos. (Editorial). Revista Direito Sanitário, v. 20 n. 2, p. 1-4, jul./out. 2019. Disponível em:

https://www.revistas.usp.br/rdisan/article/view/169636/160603. Acesso em: jul. 2020.

ARBIX, Glauco. Ciência e tecnologia em um mundo de ponta-cabeça. Revista de Estudos Avançados, n. 99, p. 65-76, 2020. Disponível em:

https://www.scielo.br/scielo.php?script=sci_arttext\&pid=S0103-

$40142020000200065 \&$ Ing=pt\&nrm=iso\&tlng=pt. Acesso em: 7 jul. 2020.

BARCELLOS, Ana Paula de. Acesso à informação: os princípios da lei 12.527/11.

Quaestio Juris, Rio de Janeiro, v. 08, n. 03, p. 1741-1759, 2015. Disponível em:

https://www.e-publicacoes.uerj.br/index.php/quaestioiuris/article/view/18818. Acesso em: 7 jul. 2020.

BAUMANN, Zygmunt. Vida líquida. [Trad. Carlos Alberto Medeiros]. Rio de Janeiro: Zahar Editor, 2007.

BRANCO, Gerson Luiz Carlos. A proteção das expectativas legitimas derivadas de confiança: elementos formadores do princípio da confiança e seus efeitos. Revista de Direito Privado, n. 12, p. 169-22, out./dez. 2002.

CANEPA, Carla. Cidades sustentáveis: o município como locus da sustentabilidade. São Paulo: RCS Editora, 2007.

D'AMORE, Rachael. Global News (11/2/2020): 'Yes, this drone is speaking to you': how China is reportedly enforcing coronavirus rules. Disponível em: https://globalnews.ca/news/6535353/china-coronavirus-drones-quarantine/. Acesso em: 7 jul. 2020.

DANTAS, Ivo; CASTRO, Gina Gouveia Pires de. Os municípios e a federação brasileira: a importância desses no contexto constitucional brasileiro. In: NASCIMENTO, Carlos Valder do; DI PIETRO, Maria Sylvia Zanella; MENDES, Gilmar Ferreira (Coord.). Tratado de Direito Municipal. Belo Horizonte: Fórum, 2018.

DIAS, Eduardo Rocha. Direito à saúde e a informação administrativa: o caso das advertências relativas a produtos perigosos. Belo Horizonte: Editora Fórum, 2008.

DONEDA, Danilo. Da privacidade à proteção de dados pessoais. 1. ed. Rio de Janeiro: Renovar, 2006.

FREITAS, André Ricardo Ribas; Napimoga, Marcelo; DONALISIO, Maria Rita. Análise da gravidade da pandemia de Covid-19. Epidemiologia Serviço de Saúde, v. 29, n.

2, 2020. Disponível em: 
https://www.scielo.br/scielo.php?script=sci_arttext\&pid=S2237-96222020000200900. Acesso em: 7 jul. 2020.

GUIMARÃES, Patrícia Borba Vilar Guimarães; XAVIER, Yanko Marcius de Alencar. Smart cities e direito: conceitos e parâmetros de investigação da governança urbana contemporânea Direito da Cidade, v. 08, n. 4, p. 1382-1380, 2016.

HARARI, Yuval Noah. The world after coronavirus Free to read(20/3/2020). Financial Times. Disponível em: https://www.ft.com/content/19d90308-6858-11ea-a3c91fe6fedcca75. Acesso em: 7 jul. 2020.

HREIBER, Anderson. A proibição de comportamento contraditório: tutela da confiança e venire contra factum proprium. 3. ed. Rio de Janeiro: Renovar, 2012.

JÚNIOR NOBRE, Edílson Pereira. O princípio da boa-fé e sua aplicação no direito administrativo brasileiro. Porto Alegre: Sérgio Antônio Fabris Editor, 2002.

KONDER, Carlos Nelson. Vulnerabilidade patrimonial e vulnerabilidade existencial: por um sistema diferenciador. Revista de Direito do Consumidor, São Paulo, v. 99, maio/jun. 2015.

LIRA, Ricardo César Pereira. Direito informal e direito formal nos centros urbanos brasileiros. Revista de Direito da Cidade, v. 7, n. 2, 2015. Disponível em: https://www.epublicacoes.uerj.br/index.php/rdc/article/view/16963/12760. Acesso em: 7 jul. 2020.

LORENZETTI, Ricardo Luis. Teoria da decisão judicial: fundamentos do Direito. [Tradução: Bruno Miragem; notas de tradução: Cláudia Lima Marques]. 2. ed. São Paulo: Revista dos Tribunais, 2010.

MARTINS-COSTA, Judith. A boa-fé no direito privado: critérios para a sua aplicação. São Paulo: Marcial Pons, São Paulo, 2015.

MORAES, Luiz Gustavo Vasquez de Moraes. A validade da distinção clássica entre direito público e direito privado no âmbito dos direitos reais mediante o princípio da função social da propriedade. [S.l.: s.n.], 2015.

MORAES, Maria Celina Bodin de. A caminho de um direito civil constitucional. In: MORAES, Maria Celina Bodin de. Na medida da pessoa humana, estudos na perspectiva civil constitucional. 1. ed. Rio de Janeiro: Renovar, 2010. P. 3-20.

NALINI, José Renato; SILVA NETO, Wilson Levy Braga da. Cidades inteligentes e sustentáveis: desafios conceituais e regulatórios. In: CORTESE, Tatiana Tucunduva Philippi; KNIESS, Cláudia Terezinha; MACCARI, Emerson Antonio (Org). Cidades inteligentes sustentáveis. Barueri, Editora Manole, 2017.

NEGREIROS, Teresa. Fundamentos para uma interpretação constitucional do princípio da boa-fé. Rio de Janeiro: Renovar, 1998.

PEIXINHO, Manuel Messias; GUERRA, Isabella Franco; NASCIMENTO FILHO, Firly (Org.). Os princípios da Constituição de 1988. 2. ed. Rio de Janeiro, Lumen Juris, 2006. 
PEREIRA, Jane Reis Gonçalves; SILVA, Fernanda Duarte Lopes Lucas da. A estrutura normativa das normas constitucionais. Notas sobre a distinção entre princípios e regras. [S.I.: s.n.], 20-?

PERLINGIERI, Pietro. Perfis de direito civil, introdução ao direito civil constitucional. Rio de Janeiro: Renovar, 2002.

SAMPAIO, Izabel Cristina da Silva. Informação ambiental: a Convenção de Aarhus e seu contributo no âmbito da União Europeia. Revista do Instituto do Direito Brasileiro, v. 2, n. 12, 2013. Disponível em: http://www.cidp.pt/publicacoes/revistas/ridb/2013/04/2013_12_00000_Capa.pdf. Acesso em: 7 jul. 2020.

SANTOS, Isabela Soares. Sistema público de saúde de qualidade torna uma cidade saudável. Carta Capital, 24 maio 2019. Disponível em: https://www.cartacapital.com.br/blogs/br-cidades/sistema-publico-de-saude-dequalidade-torna-uma-cidade-saudavel/. Acesso em: 7 jul. 2020.

SARLET, Ingo Wolfgang; MOLINARO, Carlos Alberto. O direito à informação na ordem constitucional brasileira: breves apontamentos. In: SARLET, Ingo Wolfgang; MARTOS, José Antonio Montilla; RUARO, Regina Linden (Coord.). Acesso à informação como direito fundamental e dever estatal. Porto Alegre: Livraria do Advogado, 2016.

TEPEDINO, Gustavo. Teoria dos bens e situações subjetivas reais: esboço de uma introdução. In: TEPEDINO, Gustavo. Temas de direito civil tomo Il. 1. ed. Rio de Janeiro: Renovar, 2006. p. 135-145.

TEPEDINO, Gustavo; OLIVA, Milena Donato. Teoria geral do Direito Civil. In: TEPEDINO, Gustavo (org.). Fundamentos de direito civil. Rio de Janeiro: Forense, 2020.

YANG, Yingzhi; ZHU, Julie Zhu. Coronavirus brings China's surveillance state out of the shadows. Reuters, 07 fev. 2020. Disponível em:

https://www.reuters.com/article/us-china-health-surveillance/coronavirus-bringschinas-surveillance-state-out-of-the-shadows-idUSKBN2011HO. Acesso em: 07 jul . 2020. 